\title{
REFORMA TRABALHISTA E SUAS IMPLICAÇÕES NA REPRESENTAÇÃO SINDICAL DOS TRABALHADORES
}

\author{
Alexandre Paiva \\ Universidade Federal da Grande Dourados (UFGD) \\ E-mail: alexandre.paiva@sercomtel.com.br \\ Adriana Kirchof de Brum \\ Universidade Federal da Grande Dourados (UFGD) \\ Email: adrianabrum@ufgd.edu.br
}

\begin{abstract}
RESUMO
A nova legislação brasileira que entrou em vigor em novembro de 2017, conhecida como a "Reforma Trabalhista", trouxe um novo cenário para as relações de trabalho, com repercussões nos vínculos empregatícios e também nas entidades que orbitam no entorno dessas relações, como, por exemplo, os sindicatos. Em relação às associações sindicais, os efeitos foram visivelmente contundentes uma vez que o protagonismo atribuído na elaboração de normas autônomas passou a conviver com a própria sobrevivência do sindicato ameaçada pela alteração das regras de custeio. $\mathrm{O}$ presente trabalho consiste numa breve análise histórica e legislativa do sindicalismo no país, bem como suas alterações após a vigência da Lei n. 13.467/2017 e seus reflexos nos acordos e convenções coletivas de trabalho. Trata-se de uma pesquisa qualitativa, pautada em análise bibliográfica.
\end{abstract}

Palavras-Chave: Reforma Trabalhista no Brasil; Unicidade Sindical; Liberdade Sindical.

\section{LABOR REFORM AND ITS IMPLICATIONS IN TRADE UNION REPRESENTATION}

\begin{abstract}
The new Brazilian legislation that came into force in November 2017, known as the "Labor Reform", brought a new scenario for labor relations, with repercussions on employment links and also on entities that orbit around these relations, such as unions. In relation to union associations, the effects were visibly striking once the protagonism attributed in the elaboration of autonomous norms came to live with the very survival of the union threatened by the change of the rules of costing. The present work consists of a brief historical and legislative analysis of trade unionism in the country, as well as its changes after the validity of Law n. 13.467 / 2017 and its effects on collective bargaining agreements. It is a qualitative research, based on bibliographic analysis.
\end{abstract}

Keywords: Labor Reform in Brazil; Union Unity; Freedom of Association. 


\section{INTRODUÇÃO}

A flexibilidade de direitos ou mesmo a necessidade de alterações da legislação trabalhista não é um fato inédito na sociedade brasileira. Logo em seu nascedouro, a Consolidação das Leis do Trabalho (CLT), em 1943, já previa jornada fixa de trabalho, sendo possível ao trabalhador se ativar em jornada superior de até duas horas, com posterior compensação.

A tendência de flexibilização de direitos foi presente no país durante boa parte do século XX. Nesses termos, possível verificar a Lei n. 6.019/74, que instituiu o trabalho temporário, ou a Lei n. 5.107/1966 que criou o fundo de garantia por tempo de serviço (FGTS) em substituição à estabilidade decenal prevista na CLT, ambas no período militar. Outrossim, inúmeras outras práticas foram iniciadas em larga escala na década de 1990, como a permissão de banco de horas, turnos ininterruptos de revezamento em jornadas superiores a 6 horas, ou mesmo a jornada de 12 horas de trabalho por 36 horas de descanso (comumente conhecida como 12x36), uma singularidade brasileira, conforme aponta Sadi Dal Rosso (2017: 171-251).

Nada obstante a Constituição Federal de 1988 ter solidificado direitos sociais, assegurando aos trabalhadores condições que garantam o progresso de sua condição social, o processo de globalização pelo mundo difundiu ainda mais a ideia de flexibilização e a desconstrução de direitos sociais. Esse quadro, aliás, serve para entender o contexto das reformas trabalhistas difundidas em países como Portugal, Espanha, Itália, Alemanha e, mais recentemente, Brasil.

O argumento central utilizado pelo legislativo nacional na elaboração do projeto de lei que modificou a legislação foi a necessidade de aprimorar as relações de trabalho por meio da valorização da negociação coletiva entre trabalhadores e empregadores, além de combater a informalidade. E nesse aspecto para os defensores da reforma, com amplo apoio de setores da sociedade, em especial da mídia nacional, eram necessárias alterações pontuais na engrenagem sindical a fim que as entidades de representação dos trabalhadores pudessem exercer papel singular na constituição de direitos por meio de acordos e convenções coletivas de trabalho.

De qualquer sorte, sancionada após pouco mais de seis meses de tramitação legislativa, num conturbado cenário político no país, a Lei n. 13.467/2017, conhecida como "Reforma Trabalhista", introduziu significativas alterações nas relações de trabalho. Dentre mais de duzentas modificações no texto disposto na CLT (MAIOR, 2017), possível constatar, à margem das justificativas legislativas, medidas que vieram a desestabilizar relações de trabalho, causar insegurança jurídica na relação entre patrões e empregados, bem como o acarretar enfraquecimento das organizações sindicais e, em última análise, da própria classe laboral. 
Nesse contexto, destaca-se a importância de se cotejar a atuação institucional dos sindicatos, em especial, após o período da reforma, mormente no que se refere a necessidade de melhoria das condições sociais dos trabalhadores, nos termos previstos no art. $7^{\circ}$ da Constituição Federal.

O tema em tela no presente artigo ainda é pouco explorado na academia o que imputa ao trabalho uma originalidade que o difere de outras análises. Trata-se de uma pesquisa qualitativa, básica, de cunho exploratório, pautada em análise bibliográfica, com recorte temporal, sobretudo, no período compreendido entre os anos de 2016 e 2018.

\section{ASPECTOS HISTÓRIOS DO SINDICALIMO NO BRASIL}

A gênese sindical está atrelada a movimentos operários iniciados com a intensificação do uso de máquinas e o desenvolvimento do setor industrial em substituição à produção artesanal e manufatureira entre os séculos XVIII e XIX, concomitante ao avanço do sistema de produção capitalista.

Esse é o cenário onde se desenvolveu a chamada divisão de classes. De um lado os capitalistas, detentores dos meios de produção por meio dos quais vivem da exploração da mão-deobra e, do outro lado, os chamados proletários, os quais dispõem tão somente de sua força de trabalho para a sobrevivência. Ainda de acordo com Antunes (1979: 11), “o produto criado pelo operário passou a ser apropriado pelo capitalista".

Essas circunstâncias conduziram os trabalhadores proletariados, em maior número, a se aglomerarem em flagrante atitude de defesa em relação aos mandos e desmandos dos capitalistas, mormente na busca de melhores patamares salariais (ANTUNES, 1979: 4-21).

Surgem, pois, os sindicatos como instrumentos de resistência, os quais agem resguardando individualmente a figura dos operários. Cabe a essas entidades a missão de protagonizar a garantia, segurança e estabilidade jurídica do trabalhador frente à exploração capitalista, por meio de negociações coletivas firmadas diretamente com os empregadores, como forma de aprimoramento e evolução das condições de trabalho, em especial a melhoria de salários.

Para Vladimir Ilitch Lenine (1920: 21):

Os sindicatos representaram um progresso gigantesco da classe operária nos primeiros tempos do desenvolvimento do capitalismo, visto que significavam a passagem da dispersão e da impotência dos operários aos rudimentos da união de classe. 
Esse movimento, iniciado de forma visível nos países capitalistas centrais da Europa, também pode ser constatado no Brasil. O início dos movimentos de classe no país passou a ser observado após o fim do período escravocrata em 1888 e o início da industrialização já no século XX. Marcado por ideais socialistas, comunistas e anarquistas, até a década de 1920 o país foi palco de intensa atividade operária, em especial nos estados de São Paulo e Rio de Janeiro (KAPOR; POSSEBON, 2017: 411).

Registra-se, por oportuno, que à margem de movimentos sociais esparsos, em 1903 o Decreto n. 979 faculta a organização de trabalhadores rurais em torno de sindicados (BRASIL, 2018), sendo que 1906 no Rio de Janeiro foi criada a primeira central sindical brasileira, Confederação Operária do Brasil (FÜCHTNER, 1980: 264).

Conquanto incipientes os movimentos operários, foi a partir da década de 1930 que o sindicalismo brasileiro inicia uma nova fase com o governo de Getúlio Vargas. A partir daí ocorreu:

(...) o discurso de um Estado regulador e protetor, apresentando-se como inventor da legislação social. Houve a valorização da indústria, com a política econômica voltada para o desenvolvimento da nação. O período foi marcado também pela relação mais direta com os trabalhadores e seus sindicatos, caracterizando a chamada política social, composta de leis trabalhistas, ao lado das leis previdenciárias, das leis sindicais e das leis organizadoras da Justiça do Trabalho (ALVES; KAJINO; ALVES, 2017: 111).

Segundo as mesmas autoras até o ano de 1985 o sindicalismo no Brasil foi marcado por períodos de avanço ou mesmo retrocesso, sempre condicionado pela conjuntura política nacional.

Nesse sentido, no período de 1935 a 1942, observa-se a desmobilização sindical, tendo sido fortemente retomado no período pós-guerra, em 1945, com movimentos paredistas e surgimento de sindicatos por todo país. Com o golpe militar em 1964 o sindicalismo mais uma vez se retrai, agindo praticamente de forma clandestina, ressurgindo no início da década de 1980, com destaque à fundação da Central Única dos Trabalhadores (CUT) em 1983 e às greves dos metalúrgicos no interior de São Paulo em 1984, com flagrante protagonismo dos trabalhadores e dos sindicatos no processo de redemocratização do país, cujo ápice ocorreu com a promulgação da Constituição Federal de 1988.

A partir da década de 1990, entretanto, a conjuntura política e econômica do país cria condições para o desenvolvimento de políticas neoliberais, culminando com a internacionalização da economia interna.

Para Antunes e Silva (2015: 515) “a fusão entre o neoliberalismo e reestruturação produtiva dentro de um universo conduzido pelo capitalismo financeiro gerou profundas transformações no mundo do trabalho.” As práticas neoliberais foram fortalecidas na década de 
2000, curiosamente após a vitória de um candidato para o cargo de Presidente da República, cuja história está intrinsicamente ligada ao movimento sindical.

Ainda segundo Antunes e Silva (2015: 519) o sindicalismo, fortemente arraigado pelas ideias difundidas pela Central Única dos Trabalhadores acaba por tangenciar o universo do trabalho e a luta de classes, passando a militar de forma moderada na "defesa da cidadania, desprovida de um componente acentuado de classe, além de atuar centralmente no espaço da negociação", inclusive com viés político em confrontos entre entidades sindicais, como se observa, exemplo, nos embates entre a própria CUT com a Força Sindical.

Visível, portanto, essa linha cronológica no contexto sindical nacional, o qual acompanhou em estado de (quase) letargia a reforma trabalhista, cujas alterações, prometidas como verdadeiro oásis, símbolo de modernização nas relações sindicais, se apresentaram num primeiro momento como ferramenta para o enfraquecimento dos sindicatos, mormente com relação a estrutura e seu poder negocial.

\section{ASPECTOS NORMATIVOS NO SINDICALISMO BRASILEIRO E A CONVENÇÃO N. 87 DA ORGANIZAÇÃO INTERNACIONAL DO TRABALHO (OIT)}

Em sua edição original, datada de 19 de abril de 1943 (BRASIL, 2018), a Consolidação das Leis do Trabalho definiu os sindicatos como associações de defesa de direitos de trabalhadores e, inclusive, empregadores (art. 511) ${ }^{1}$, os quais deveriam ser registrados em órgãos governamentais $(\text { art. } 512)^{2}$, com limitação de um único órgão representativo na base limitada por distrito ou município (art. 516 e art. 517) ${ }^{3}$.

Ainda em conformidade com a legislação vigente à época cabia aos sindicatos, dentre outras prerrogativas, firmar os chamados contratos coletivos de trabalho (art. 513) $)^{4}$ e instituir contribuições conhecida como imposto sindical de caráter obrigatório à toda categoria (art. 578 e art. 579) $)^{5}$.

As bases jurídicas fixadas na década de 1940, em grande parte, foram recepcionadas pela Constituição Federal de 1988, a qual fixou as seguintes balizas para o sindicalismo no país:

Art. $8^{\circ}$ É livre a associação profissional ou sindical, observado o seguinte:

I - a lei não poderá exigir autorização do Estado para a fundação de sindicato, ressalvado o registro no órgão competente, vedadas ao Poder Público a interferência e a intervenção na organização sindical;

II - é vedada a criação de mais de uma organização sindical, em qualquer grau, representativa de categoria profissional ou econômica, na mesma base territorial, que será definida pelos trabalhadores ou empregadores interessados, não podendo ser inferior à área de um Município; 
III - ao sindicato cabe a defesa dos direitos e interesses coletivos ou individuais da categoria, inclusive em questões judiciais ou administrativas;

IV - a assembleia geral fixará a contribuição que, em se tratando de categoria profissional, será descontada em folha, para custeio do sistema confederativo da representação sindical respectiva, independentemente da contribuição prevista em lei;

V - ninguém será obrigado a filiar-se ou a manter-se filiado a sindicato;

VI - é obrigatória a participação dos sindicatos nas negociações coletivas de trabalho;

VII - o aposentado filiado tem direito a votar e ser votado nas organizações sindicais;

VIII - é vedada a dispensa do empregado sindicalizado a partir do registro da candidatura a cargo de direção ou representação sindical e, se eleito, ainda que suplente, até um ano após o final do mandato, salvo se cometer falta grave nos termos da lei.

Parágrafo único. As disposições deste artigo aplicam-se à organização de sindicatos rurais e de colônias de pescadores, atendidas as condições que a lei estabelecer. (BRASIL, 1988)

O princípio da liberdade sindical está estampado no caput e no inciso primeiro, sendo que no inciso quinto há a chamada liberdade de sindicalização. A rigor referido princípio serve (ou deveria cumprir esse papel) de alicerce para albergar os demais princípios e disposições referentes às atribuições sindicais.

Ocorre, entretanto, que a liberdade sindical esbarra logo no inciso segundo no chamado princípio da unicidade sindical, ou seja, a norma constitucional deu validade ao art. 511 da CLT que limita a existência de um único sindicato representativo numa determinada base territorial.

Nesse sentido, ressalta Barros:

(...) Os críticos da unicidade sindical afirmam que ela representa uma violação aos princípios democráticos e, mais especificamente, à liberdade sindical, impedindo aos componentes de determinada categoria a livre escolha de sindicato para se filiarem. Sublinham a importância da saudável competição entre as entidades, evitando a acomodação de lideranças sindicais, advinda da exclusividade de representação classista. Ressaltam que os países nos quais as reivindicações são mais expressivas adotam a pluralidade, a qual não deverá ser obrigatória, mas facultativa, de modo que os trabalhadores, se assim pretenderem, podem reunir-se em representações unitárias (...). (2017: 904)

De igual forma, possível observar que o inciso quarto, ao instituir a contribuição sindical de caráter obrigatório, originariamente chamado de imposto sindical (CLT, art. 579), compromete o texto constitucional.

Para Alice Monteiro de Barros (2017: 904):

no Brasil, a legislação em vigor obriga todos os integrantes das categorias profissionais ou econômicas, seja, ou não associação aos sindicatos, a pagar o imposto sindical, eufemisticamente denominado contribuição sindical, verdadeiro atentado ao princípio da liberdade sindical mantido pela Constituição de 1988. (2017: 904)

A crítica em desfavor da instituição da unicidade sindical e da obrigatoriedade da contribuição ganha maiores relevos quando analisada a Convenção n. 87 da Organização 
Internacional do Trabalho (OIT) a qual veda implicitamente a obrigatoriedade de contribuições, ao mesmo tempo em que acolhe o princípio da pluralidade sindical.

Aprovada na $31^{a}$ reunião da Conferência Internacional do Trabalho em 1948, a convenção entrou em vigor em 1950, tendo sido ratificada pela maioria esmagadora de seus membros (mais de 150, dentre os 183 países membros), com destaque para França, Reino Unido, Portugal, Espanha, Bélgica, Itália e México. Tem como tema a tutela da liberdade sindical a qual é tratada em quatro quadrantes: o direito de fundar sindicatos, administrar sindicatos, além da forma de atuação dos sindicatos e o direito de filiação ou desfiliação de uma entidade sindical (ORGANIZAÇÃO INTERNACIONAL DO TRABALHO, 2018).

O Brasil não ratificou aludida convenção. O Presidente da República Eurico Gaspar Dutra encaminhou para o Poder Legislativo, em 1949, o pedido de autorização para ratificação o qual, permanece sem definição até o momento, apesar da aprovação pela Câmara dos Deputados em 1984 (BARROS, 2017: 904). Em consulta ao sítio do Senado Federal, possível constatar o requerimento para uma audiência pública para tratar do tema na Comissão de Direitos Humanos e Legislação Participativa, cuja tramitação foi “encerrada”, sem a publicação dos motivos (BRASIL, 2015).

Justifica-se que a não incorporação da convenção no ordenamento jurídico tem por entrave, em especial, o princípio da unicidade e a obrigatoriedade na contribuição sindical, além do sistema confederativo no país (CLT, art. 533) ${ }^{6}$. Um verdadeiro, paradoxo, bem verdade, a se considerar a liberdade plena prevista no art. $8^{\circ}$ como já se destacou.

O fato é que a convenção integra o catálogo das chamadas convenções fundamentais da OIT e, como tal, deveria ser adotada por todos os seus integrantes. A postura política adotada no país, no entanto, deixa o Brasil numa posição vexatória e injustificável, na medida em que, no entendimento do ex-ministro do Tribunal Superior do Trabalho, Almir Pazzianotto Pinto, expõe sua fragilidade diante de "pressões de entidades constituídas sob a égide do modelo corporativista, e as cobranças internas e externas pela adoção de uma das diretrizes fundamentais da Organização Internacional do Trabalho" (SENADO, 2007).

A reforma trabalhista talvez fosse o grande momento para se equacionar a inquietude, política, social e jurídica em torno dessa questão. No entanto, o que se observou é que as alterações vieram apenas a legitimar a agenda neoliberal no país a qual não tem por prioridade amenizar os impactos da exploração, ou mesmo minorar a retirada de direitos, tampouco dar garantia plena para a liberdade sindical prevista no texto constitucional. 


\section{ENFRAQUECIMENTO SINDICAL APÓS A REFORMA TRABALHISTA}

Para Noam Chomsky (2014: 56), a mídia utiliza-se de propagandas para o controle de massas e até mesmo como forma de manobra e convencimento da sociedade. Para tanto, manipula informações e amedronta a população a fim de criar um cenário de instabilidade como forma de alcançar consenso sobre determinado tema.

A reforma trabalhista apresentada pelo Congresso, defendida pelo Palácio do Planalto e amplamente difundida pela imprensa entre o final de 2016 e meados de 2017 se encaixa perfeitamente nesse pensamento desenvolvido pelo professor estadunidense.

Com efeito, tendo com um dos pilares da reforma a possibilidade de flexibilização de direitos mediante negociações coletivas (a chamada prevalência do negociado sobre o legislado), a ideia sustentada pelo legislador e amplamente difundida na sociedade, principalmente pelos grandes veículos de comunicação, era a necessidade de "fortalecer as associações sindicais" as quais deveriam exercer papel de destaque na promoção de direitos aos trabalhadores, a fim de "modernizar as relações de trabalho", "combater a informalidade" e "diminuir as taxas de desemprego".

No que se refere ao sindicalismo, objeto do presente estudo, conquanto o diálogo sobre o tema passe pela garantia da ampla liberdade, mediante o fim da unicidade sindical e também da obrigatoriedade das contribuições, a estratégia adotada ignorou a questão, especialmente o trâmite legislativo sobre a Convenção n. 87 da OIT, e mirou tão somente o fim das contribuições.

O discurso cuidadosamente elaborado para tanto, pode ser resumido no parecer da Câmara dos Deputados nos seguintes termos:

(...) A proposta de se estimular o resultado das negociações coletivas, contudo, tem que estar diretamente relacionada com a estrutura sindical em que as entidades sejam mais representativas e mais democráticas. Embora reconheçamos a existência de inúmeros sindicatos altamente representativos, não podemos fechar os olhos para a outra realidade do nosso sistema sindical, em que proliferam sindicatos de fachada. E, nesse ponto, temos a convicção de que a sugestão de retirar a natureza de imposto da contribuição sindical, tornando-a optativa, será de fundamental importância no processo de fortalecimento da estrutura sindical brasileira. (...) Os sindicatos, sejam eles classistas ou patronais, não mais poderão ficar inertes, sem buscar resultados efetivos para suas respectivas categorias, respaldados em uma fonte que não seca, que eles recebem independentemente de apresentarem quaisquer resultados. Aqueles que se sentirem efetivamente representados por seus sindicatos, trabalhadores ou empregadores, pagarão suas contribuições em face dos resultados apresentados. Os que não tiverem resultados a apresentar, aqueles que forem meros sindicatos de fachada, criados unicamente com o objetivo de arrecadar a contribuição obrigatória, esses estarão fadados ao esquecimento. (CAMARA, 2016: 28)

O consenso em torno dessa ideia foi pacificado no imaginário dos trabalhadores e de toda a sociedade até porque a contribuição obrigatória é fruto de um anacronismo legal prevalente no 
ordenamento jurídico nacional, como já se viu. No entanto, emergem as seguintes dúvidas: e quanto aos sindicatos de fachada, qual a alternativa que se apresentará aos trabalhadores? Como seus direitos serão potencializados? Se os direitos deverão ser negociados, com a extinção de alguns sindicatos esses trabalhadores também estarão fadados ao esquecimento?

O fato é que a ideia de extinguir a obrigatoriedade da contribuição sem permitir a pluralidade sindical não se apresenta como um meio eficaz para a garantia da ampla liberdade sindical, tampouco para a difusão de instrumentos coletivos e a promoção de direitos. São elementos entrelaçados não podendo haver a alteração de uma parte "sem que haja a alteração do todo, sob pena de uma desarmonia que atenta contra os comandos constitucionais", nas palavras da Ministra do Supremo Tribunal Federal, Rosa Weber (BRASIL, 2018: 1).

Ainda valendo-se do parecer já mencionado, necessário frisar a justificativa do legislador para a manutenção da unicidade sindical:

(...) Por outro lado, não estamos alterando aspectos relativos à estrutura sindical, como a unicidade sindical, por exemplo, pois esse assunto deve ser tratado em nível constitucional. Todavia a transformação da natureza da contribuição sindical de obrigatória para optativa servirá como primeiro passo para que a reforma sindical seja discutida pelas partes interessadas. É o que esperamos (...). (CAMARA, 2016: 29)

A despeito desse panorama, a Lei n. 13.467/2017 passou a vigorar em 10.11.2017 e modificou, dentre outros dispositivos, a redação do art. $545^{7}$ (e seguintes) da CLT tornando facultativa a contribuição sindical, o que foi posteriormente chancelado pelo Supremo Tribunal Federal, no final do mês de junho de 2018, com a declaração de constitucionalidade da norma na ADI n. 5794 e na ADC n. 55. A unicidade sindical, por sua vez, permanece incólume no ordenamento jurídico nacional.

Nada obstante, pouco tempo depois da alteração legislativa, a sociedade pode perceber que a reforma não passou de um discurso retórico, cujo objetivo era desconstruir relações sociais firmadas em torno do trabalho. Com efeito, as alterações legislativas não apresentaram avanços no papel que se prestou a cumprir, tanto com relação à minoração do desemprego e da informalidade, quanto no fortalecimento das associações sindicais, ou mesmo na modernização das relações trabalhistas.

Nesses termos, realizada pelo Instituto Brasileiro de Geografia e Estatísticas (IBGE), a Pesquisa Nacional por Amostra de Domicílios (PNAD) demonstra que os números do desemprego e informalidade no país continuam expressivos (em torno de 13 milhões de pessoas sem ocupação e 11 milhões em empregos sem os haveres contratuais formalmente assegurados), sem grandes 
alterações com relação às taxas de desemprego, inclusive com a elevação da taxa de informalidade, tomando como comparação o primeiro trimestre dos anos de 2017 e 2018 (PERET, 2018).

Outrossim, com relação a pactuação de direitos por meio de acordo e convenções coletivas de trabalho, os dados estatísticos apresentados pelo Departamento Intersindical de Estatística e Estudos Socioeconômicos (Dieese), no mês de maio de 2018, despertam especial atenção. Os índices apurados apontam para uma queda acentuada de 29\% no número de negociações coletivas registradas no Ministério do Trabalho no primeiro trimestre de 2018, se comparada ao primeiro trimestre de 2017 e à média dos últimos cinco anos (DIEESE, 2018).

A justificativa para esse quadro, ainda conforme a pesquisa, consiste na alteração da forma de custeio dos sindicatos, com o fim da obrigatoriedade das contribuições, fato que culminou na desmobilização dos trabalhadores e na incapacidade de manutenção administrativa dos sindicatos e, por consequência, o endurecimento do empresariado nas negociações coletivas e diminuição dos índices salariais.

Esse cenário pode ser constatado cotidianamente por todo país. Os meios de comunicação, que desempenharam papel singular na defesa da reforma, noticiam a todo o instante a vertiginosa queda de receita nas entidades sindicais, e a dificuldade na representação dos trabalhadores como informou o diretor técnico do Dieese, Clemente Ganz Lúcio ao periódico eletrônico Rede Brasil Atual. (REDE BRASIL ATUAL, 2018)

No âmbito local, o Sindicato dos Trabalhadores nas Indústrias do Açúcar, Etanol e Bioenergia de Caarapó, MS, com 520 trabalhadores em sua base territorial, noticia que a queda de receita da entidade gira em torno de $90 \%$, o que resultou na redução da estrutura física e administrativa do sindicato, inclusive com dispensa dos funcionários. Mas o impacto ainda maior evidenciado pela entidade foi a desmobilização dos trabalhadores, apreensivos com a perda dos postos de trabalho, e, por consequência, o enfraquecimento nas negociações coletivas, que em 2018 se limitaram à manutenção dos direitos conquistados nos anos anteriores (informação verbal) ${ }^{8}$.

Todas essas circunstâncias autorizam a concluir que o ardiloso discurso adotado para justificar a necessidade da reforma foi um instrumento utilizado para desestabilizar a estrutura de resistência representada pelos sindicatos e, em última instância, fragilizar ainda mais a figura do trabalhador perante o capital.

Essa estratégia não é um caso fortuito, fruto do mero acaso. Valendo-se novamente de Chomsky:

(...) é preciso manter as pessoas atomizadas, segregadas e isoladas. Elas não podem se organizar, porque assim elas podem deixar de ser apenas espectadoras da ação. Na verdade, se um grande número de pessoas com recursos limitados conseguisse se juntar para 
ingressar na política, elas poderiam vir a se tornar participantes. E isso, de fato, é ameaçador. (2014: 12)

O enfraquecimento do sindicalismo não significa apenas um retrocesso nas relações coletivas de trabalho ou um prejuízo frontal na necessidade de melhoria das condições sociais do trabalhador. O prejuízo é muito maior: é um atentado aos próprios fundamentos do Estado Democrático de Direito na medida em que vulnera a dignidade e a cidadania do homem trabalhador, além dos valores sociais do trabalho podendo comprometer, inclusive, a livre iniciativa.

Diante dessa premissa conclui-se que há aqui um processo de transformação importante nas relações de trabalho, no tocante à questão do sindicalismo, que deslinda a possibilidade de uma frente de investigação que veja como esse tema é impactado pela atual reforma. Numa perspectiva de pesquisa, pode-se dizer que caberá aos sindicatos o grande desafio de entrincheirar novamente em busca de melhorias nas condições de trabalho a fim de evitar o retrocesso social que voltou a amedrontar a vida dos trabalhadores.

\section{CONSIDERAÇÕES FINAIS:}

O presente artigo buscou fazer uma análise contextualizando a reforma trabalhista ocorrida no Brasil - Lei n. 13.467/2017 - e o poder de representatividade dos trabalhadores por meio das entidades sindicais.

Partindo do contexto histórico, é possível avaliar o desenvolvimento de institutos jurídicos no campo sindical, que culminou com os pressupostos alicerçados no exercício da liberdade sindical, assegurado no art. $8^{\circ}$ da CLT.

Nesse panorama, a não ratificação da Convenção n. 87 da Organização Internacional do Trabalho, em vigor desde a década de 1950, caminha na contramão da evolução jurídica do sindicalismo no Brasil, uma vez que obstaculiza seu amplo exercício ao instituir a obrigatoriedade da contribuição e a unicidade sindical.

Com a reforma trabalhista ocorrida em 2017, o país perdeu um grande momento para reverter essa situação. $\mathrm{Na}$ verdade, a despeito do discurso adotado na tentativa de criar um consenso positivo sobre a necessidade das alterações legislativas, houve um agravamento ainda maior no cotidiano laboral e para a sociedade em geral na medida em que as alterações legislativas tornaram facultativas as contribuições sindicais, ficando mantido, no entanto, o princípio da unicidade.

A medida atingiu frontalmente os sindicatos que tinham na contribuição a sua maior fonte de receita. Reflexo disso pode ser constatado na significativa queda no número de convenções e 
acordos coletivos de trabalho registrados no Ministério do Trabalho no primeiro trimestre de 2018 (2.808), se comparado ao mesmo período no ano de 2017 (3.939), o que demonstra o enfraquecimento dos órgãos representantes dos trabalhadores, conforme dados estatísticos apurados pelo Dieese no mês de maio de 2018.

À toda evidência, atribuir ampla validade à reforma, sem a correta leitura do texto constitucional, é negar o desenvolvimento sindical e os próprios fundamentos do Estado Democrático de Direito ou, como sustentou o Conselho Nacional dos Direitos Humanos em nota técnica (2017), a reforma pode representar "o mais grave ataque aos direitos sociais, ao direito do trabalho e aos Direitos Humanos no Brasil, pois seu alcance vai além da simples relação trabalhista tendo impactos profundos no sistema de proteção social e na economia do país".

O momento exige profunda reflexão e a cautela necessária de órgãos que atuam para salvaguardar direitos sociais que foram conquistados ao longo de anos pela sociedade brasileira. A ideia de flexibilizar direitos de forma irrestrita e desarticular associações sindicais implicará, seguramente, no enfraquecimento da classe trabalhadora em face do capital, cuja atuação se respalda em legislações flexíveis a fim de dificultar a efetividade de direitos sociais nos países de capitalismo dependente (SEVERO; SOUTO MAIOR, 2017).

\section{REFERÊNCIAS:}

ALVES, Juliana Vieira; KAJINO, Lucia Midori; ALVES, Miriam Ramalho. LUTAS SOCIAIS E SINDICALISMO NO BRASIL. 2017: In: CUEVAS, Ana Carolina Bianchi Rocha; MAIOR, Giovanna Maria Magalhaes Souto; RODRIGUES, Renata do Nascimento Santos (Org.).

RETALHOS HISTÓRICOS DO DIREITO DO TRABALHO. São Paulo: Ltr.

ANTUES, Ricardo. 1979. O QUE É SINDICALISMO. 2. ed. São Paulo: Brasiliense.

ANTUNES, Ricardo; SILVA, Jair Batista da. PARA ONDE FORAM OS SINDICATOS? Do sindicalismo de confronto ao sindicalismo negocial. 2015. Disponível em:

$<$ http://www.scielo.br/scielo.php?pid=S0103-49792015000300511\&script=sci_abstract\&tlng=pt $>$. Acesso em: 21 ago. 2018.

BARROS, Alice Monteiro de. 2017. CURSO DE DIREITO DO TRABALHO. São Paulo: Ltr.

BRASIL. DECRETO N. 979/1903. 2018. Disponível em:

$<$ http://www.planalto.gov.br/ccivil_03/Decreto/Antigos/D0979.htm>. Acesso em: 17 ago. 2018. . Câmara dos Deputados. Legislação Informatizada - DECRETO-LEI No 5.452, DE $1^{\circ}$

DE MAIO DE 1943 - Publicação Original. 1943. Disponível em:

$<$ http://www2.camara.leg.br/legin/fed/declei/1940-1949/decreto-lei-5452-1-maio-1943-415500publicacaooriginal-1-pe.html>. Acesso em: 21 ago. 2018. 
. CONSTITUIÇÃO FEDERAL. São Paulo: Saraiva, 2018.

. Senado Federal. Requerimento Comissão de Direitos Humanos e Legislação

Participativa ${ }^{\circ}$ 39, de 2015. 2015. Disponível em:

$<$ https://www25.senado.leg.br/web/atividade/materias/-/materia/120266>. Acesso em: 25 ago.

2018.

. Supremo Tribunal Federal. STF declara constitucionalidade do fim da contribuição sindical obrigatória. 2018. Disponível em:

$<$ http://www.stf.jus.br/portal/cms/verNoticiaDetalhe.asp?idConteudo=382819>. Acesso em: 25 ago. 2018.

CAMARA. PROJETO DE LEI No 6.787, DE 2016. Disponível em:

$<$ http://www.camara.gov.br/proposicoesWeb/prop_mostrarintegra?codteor=1544961>. Acesso em: 25 ago. 2018.

CASEMIRO, Armando. 2017. CLT. São Paulo: Ltr.

CHOMSKY, Noam. 2014. MIDIA: PROPAGANDA POLÍTICA E MANIPULAÇÃO. São Paulo: Martins Fontes.

DIEESE, Departamento Intersindical de Estatística e Estudos. BOLETIM DE CONJUNTURA. 2018. Disponível em:

$<$ https://www.dieese.org.br/boletimdeconjuntura/2018/boletimConjuntura014.pdf $>$. Acesso em: 25 ago. 2018

FÜCHTNER, Hans. 1980. Os Sindicatos Brasileiros-organização e função Política. Rio de Janeiro: Edições Graal.

HUMANOS, Conselho Nacional de Direitos. NOTA PÚBLICA DO CONSELHO NACIONAL DOS DIREITOS HUMANOS (CNDH) CONTRA A REFORMA TRABALHISTA. 2017.

Disponível em: <http://www.mdh.gov.br/informacao-ao-cidadao/participacao-

social/old/cndh/mocoes/20170824NotacontraaReformaTrabalhista.pdf>. Acesso em: 1 set. 2018.

LENINE, Vladimir Ilitch. Esquerdismo: Doença Infantil do Comunismo. 1920. Disponível em: $<$ http://www.dominiopublico.gov.br/download/texto/ma000010.pdf $>$. Acesso em: 16 ago. 2018.

MAIOR, Jorge Luis Souto; SEVERO, Valdete Souto. APRESENTAÇÃO. 2017. In: MAIOR, Jorge Luis Souto; SEVERO, Valdete Souto (Org.). RESISTÊNCIA: APORTES TEÓRICOS

CONTRA O RETROCESSO TRABALHISTA. São Paulo: Expressão Popular.

KAPOR, Tatiana Silverio; POSSEBON, Maisa Moreno (Org.). A LIBERDADE SINDICAL: O MOVIMENTO SINDICAL BRASILEIRO, A UNICIDADE SINDICAL E A "REFORMA TRABALHISTA". 2017. In: MAIOR, Jorge Luis Souto; SEVERO, Valdete Souto (Org.).

RESISTÊNCIA: APORTES TEÓRICOS CONTRA O RETROCESSO TRABALHISTA. SÃo Paulo: Express ̃̃o Popular.

PAZZIANOTTO PINTO, Almir. Liberdade Sindical. O Estado de São Paulo, 24/02/2007, Espaço Aberto. Disponível em: 
$<$ https://www2.senado.leg.br/bdsf/bitstream/handle/id/325660/noticia.htm?sequence=>. Acesso em: 31 ago. 2018.

PERET, Eduardo. Desocupação fica estável, mas informalidade aumenta em maio. 2018. Disponível em: $<$ https://agenciadenoticias.ibge.gov.br/agencia-noticias/2012-agencia-denoticias/noticias/21582-desocupacao-fica-estavel-mas-informalidade-aumenta-em-maio $>$. Acesso em: 31 ago. 2018.

\section{ORGANIZAÇÃO INTERNACIONAL DO TRABALHO. C087 - Liberdade Sindical e Proteção ao Direito de Sindicalização. 2018. Disponível em: \\ $<$ https://www.ilo.org/brasilia/convencoes/WCMS_239608/lang--pt/index.htm>. Acesso em: 25 ago. 2018.}

\section{REDE BRASIL ATUAL. Com reforma trabalhista, sindicatos perdem $80 \%$ da receita no primeiro trimestre. 2018. Disponível em:}

$<$ https://www.redebrasilatual.com.br/trabalho/2018/05/com-reforma-trabalhista-sindicatos-perdem80-das-receitas-no-1o-trimestre>. Acesso em: 25 ago. 2018.

\section{NOTAS:}

1 Art. 511. É lícita a associação para fins de estudo, defesa e coordenação dos seus interesses econômicos ou profissionais de todos os que, como empregadores, empregados, agentes ou trabalhadores autônomos ou profissionais liberais exerçam, respectivamente, a mesma atividade ou profissão ou atividades ou profissões similares ou conexas. $\S$ $1^{\circ}$ A solidariedade de interesses econômicos dos que empreendem atividades idênticas, similares ou conexas, constitui o vínculo social básico que se denomina categoria econômica. $\S 2^{\circ}$ A similitude de condições de vida oriunda da profissão ou trabalho em comum, em situação de emprego na mesma atividade econômica ou em atividades econômicas similares ou conexas, compõe a expressão social elementar compreendida como categoria profissional. $\S 3^{\circ}$ Categoria profissional diferenciada é a que se forma dos empregados que exerçam profissões ou funções diferenciadas por força de estatuto profissional especial ou em consequência de condições de vida singulares. $\S 4^{\circ}$ Os limites de identidade, similaridade ou conexidade fixam as dimensões dentro das quais a categoria econômica ou profissional é homogênea e a associação é natural.

2 Art. 512. Somente as associações profissionais constituídas para os fins e na forma do artigo anterior e registadas de acordo com o art. 558, poderão ser reconhecida como sindicatos e investidas nas prerrogativas definidas nesta lei.

${ }^{3}$ Art. 516. Não será reconhecido mais de um sindicato representativo da mesma categoria econômica ou profissional, ou profissão liberal, em uma dada base territorial.

Art. 517. Os sindicatos poderão ser distritais, municipais, intermunicipais, estaduais e interestaduais. Excepcionalmente, e atendendo às peculiaridades de determinadas categorias ou profissões, o ministro do Trabalho, Indústria e Comércio poderá autorizar o reconhecimento de sindicatos nacionais. $\S 1^{\circ} \mathrm{O}$ ministro do Trabalho, Indústria e Comércio, outorgará e delimitará a base territorial do sindicato. $\S 2^{\circ}$ Dentro da base territorial que lhe for determinada é facultado ao sindicato instituir delegacias ou secções para melhor proteção dos associados e da categoria econômica ou profissional ou profissão liberal representada.

${ }^{4}$ Art. 513. São prerrogativas dos sindicatos: a) representar, perante as autoridades administrativas e judiciárias os interesses gerais da respectiva categoria ou profissão liberal ou interesses individuais dos associados á atividade ou profissão exercida; b) celebrar contratos coletivos de trabalho; c) eleger ou designar os representantes da respectiva categoria ou profissão liberal; d) colaborar com o Estado, como órgãos técnicos e consultivos, no estudo e solução dos problemas que se relacional com a respectiva categoria ou profissão liberal; d) solução dos problemas que se relacionam com a respectiva categoria ou profissão liberal; e) impor contribuições a todos aqueles que participam das categorias econômicas ou profissionais ou das profissões liberais representadas.

${ }^{5}$ Art. 578. As contribuições devidas aos sindicatos pelos que participem das categorias econômicas ou profissionais ou das profissões liberais representadas pelas referidas entidades, serão, sob a denominação do "Imposto Sindical", pagas, recolhidas e aplicadas na forma estabelecida neste capítulo.

Art. 579. O imposto sindical é devido, por todos aqueles que participarem de uma determinada categoria econômica ou profissional, ou de uma profissão liberal, em favor do sindicato representativo da mesma categoria ou profissão ou inexistindo este na conformidade do disposto no art. 581. 
${ }^{6}$ Art. 533 - Constituem associações sindicais de grau superior as federações e confederações organizadas nos termos desta Lei.

${ }^{7}$ Art. 545. Os empregadores ficam obrigados a descontar da folha de pagamento dos seus empregados, desde que por eles devidamente autorizados, as contribuições devidas ao sindicato, quando por este notificados.

${ }^{8}$ Informação fornecida por José Carlos Camargo Roque, Procurador Jurídico da entidade, em 30.8.2018.

\section{AUTORES:}

\section{Alexandre Paiva}

Mestrando do curso de Pós-Graduação em Fronteiras e Direitos Humanos da Universidade Federal da Grande Dourados (UFGD). Analista Judiciário do Tribunal Regional do Trabalho da 24a Região.

\section{Adriana Kirchof de Brum}

Doutora em Economia na Universidade Federal do Rio Grande do Sul (UFRGS), professora e pesquisadora da Universidade Federal da Grande Dourados (UFGD). 